\title{
Passos gravados nas cidades ${ }^{1}$
}

\section{Mónica Guerreiro}

\author{
Visões Úteis, Cadernos 111 \\ [Coma profundo + Errare], Porto, \\ edição de autor, 2006, 72 pp.
}

Há algo na noção de solidão que atrai antepassados e contemporâneos. A deambulação solitária por um determinado espaço - mental ou físico - corresponde, nas mitologias urbanas, a uma sensação de poder: refém de uma cidade, enclausurado nos seus labirintos, o passeante é livre de sobre ela pensar e escrever o que quiser. Multiplicam-se as histórias de liberdade permitidas ou incitadas pela radical experiência da cidade: será preciso convocar o flâneur? Decidido, o transeunte traça o seu próprio percurso, não deixa que o façam por si.

Este texto é uma versão revista da comunicação proferida aquando do

lançamento desta publicação, na loja FNAC de Santa Catarina, no Porto, a 5 de Maio de 2006.

${ }^{2}$ Informações adicionais sobre o trabalho desta

artista, que já criou

audiowalks em Florença, Londres, São Francisco e

Nova lorque, em

http://www.bomb magazine.com/cardiff]

cardiff.html (uma

entrevista de Atom

Egoyan), em http://www.artcritical.

com/ludwin/

VLCardiff.htm (uma critica de Victoria Ludwin) ou em http://hirshhorn.si.edu/ exhibitions/description

asp?ID=20 (uma

entrevista da curadora do projecto, Kelly Gordon).

${ }^{3} 0$ trabalho referido pelo Visões Úteis é Missing Voice (case study B), de 2000. Uma abordagem critica a este trabalho está

disponivel em

http://www.artfocus. com/JanetCardiff.html.
Frequentemente, para aqueles com sorte de habitar ou visitar uma cidade assim localizada, esse caminho vai ter ao mar.

Mais significativamente afagadas por rios do que por mares, Porto e Parma terão em comum o facto de sobre as narrativas de si nascentes o Visões Úteis ter construido outras, que traduzem uma dramatização da experiência da solidão. Afinal, o rasto dos meus passos não é consequência do invisivel determinismo do desenho urbanístico mas sim de um conjunto de decisões, influências, pressões ou curiosidades que, sopesadas, me incitam a seguir por ali. Estes traços marcados sobre a cidade, que a cidade lembra e que o caminhante tende a esquecer, deram ao colectivo teatral matéria para pensar uma forma de devolver aos habitantes ou visitantes tornados espectadores de uma criação artística - as memórias deixadas no sulco dos passeios por passagens de homens (personagens da cidade) cuja marca definitivamente alterou a percepção sobre como a cidade se transmite a quem, agora, a atravessa. Que a forma encontrada para propiciar essa passagem seja uma gravação sonora, e que o meio de usufruir o espectáculo seja um passeio, solitário, a pé, podia ser não mais que um conjunto de circunstâncias. Mas a experiência de Coma profundo e de Errare mostram à saciedade que o formato não só não negligencia o propósito como, afinal, se afigura como o que melhor o serve.

0 conceito audiowalk não é invenção recente. Qualquer habituado frequentador de museus conhece o sistema de auscultadores multilingue que, por razão de captação rádio, transmite ao ouvinte os conteúdos específicos acerca da sala onde se encontra. As transferências sociais desta forma privilegiada de comunicação (porque respeita os diferentes ritmos de cada um), depois de saturada a via do turismo, chegaram a dada altura às artes, como é habitual no sistema (ou não fosse a criação artística o mais hábil parasita - e regurgitador - de soluções e

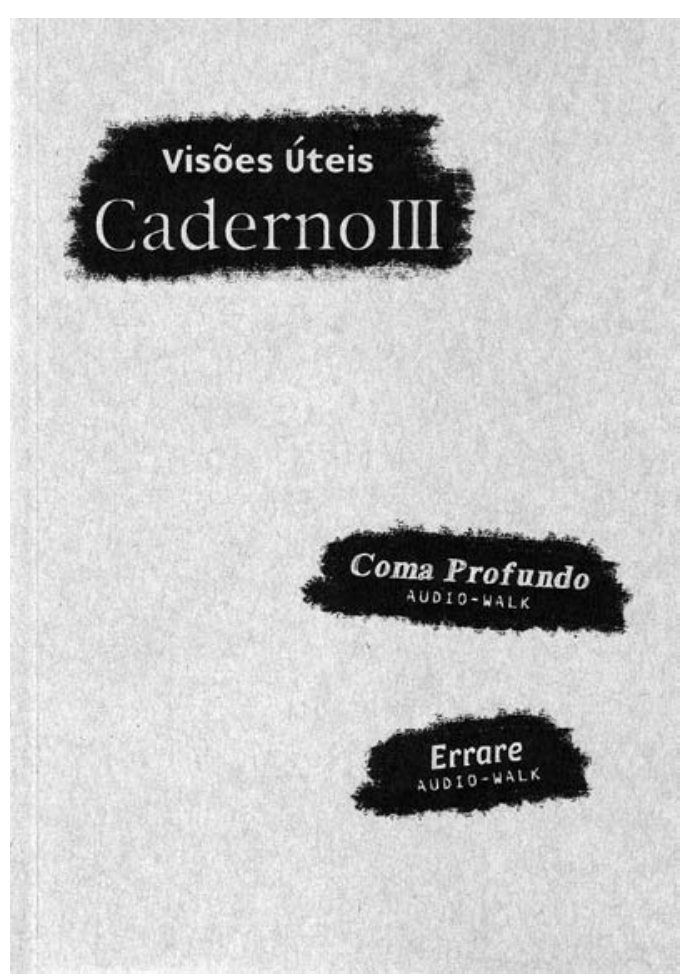

fórmulas). A canadiana Janet Cardiff' ${ }^{2}$ um exemplo entre vários, é aquela que directamente o Visões Úteis responsabiliza ${ }^{3}$ por ter experimentado, de forma considerada feliz, um modelo de narrativa auditiva, "vagamente policial", seguindo um percurso por uma cidade. Ao tomar contacto com as criações desenvolvidas pelo grupo (de 2002 e 2004, que em 2006 são objecto de edição num único volume), concluímos que não se afastaram daquelas premissas. Que são, sucintamente: objectos realizados sob a forma de um teatro onde se vai, mas que apenas a nossa presença concretiza; um teatro cujos corpos se manifestam através de um pretérito, do pensamento e do discurso construídos sobre o património edificado; um teatro que, como sempre, se funda na relação do olhar entre quem vê e quem é visto - só que, aqui, quem é visto já partiu, quem vê não sabe se está ou não a ser visto, e não antecipa se vai mesmo ver alguém. Porque o teatro acontece misturado com o resto da cidade, e essa diferença é tão difícil de perceber que cada casa, cada esquina e cada rua se transformam em actores de uma trama policial. E se falo em teatro é por isto: as estratégias a que recorre o audiowalk são efectivamente subsidiárias do jogo dramático. Sabemos, porém, ser Errare um projecto apoiado no âmbito da recém instituída, para efeitos de financiamento público, área da 


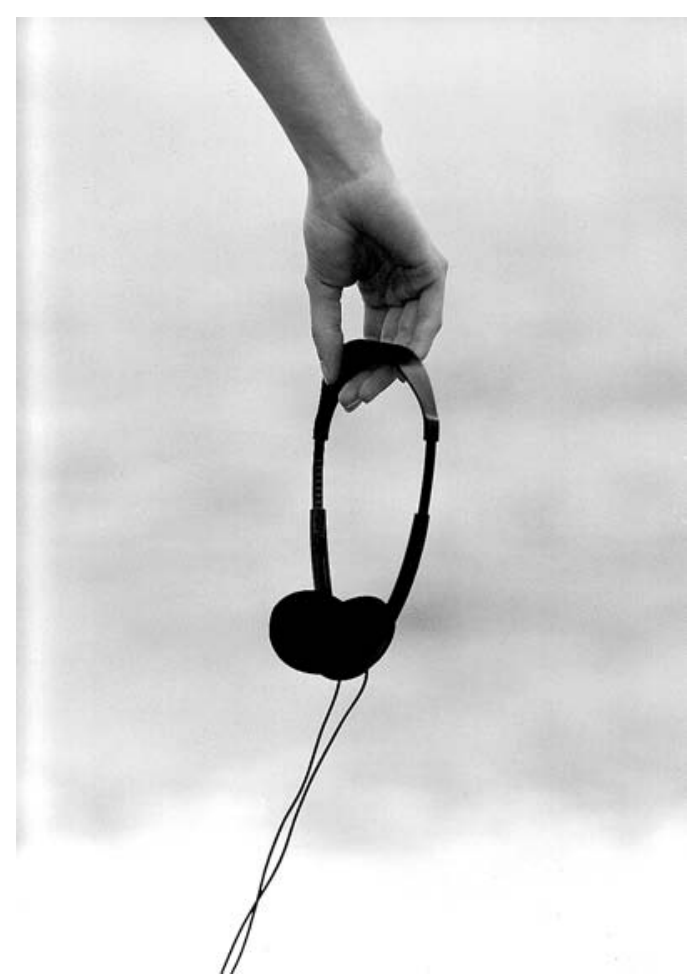

transdisciplinaridade. Daí, talvez a disciplina teatral não resolva totalmente os problemas de categorização de objectos como estes (detenhamo-nos no papel do espectador - sujeito, interlocutor, destinatário ou, como aqui, veículo da acção?).

Há, na construção ficcional dos autores (e trabalharam na dramaturgia Ana Vitorino, Carlos Costa, Catarina Martins, Pedro Carreira e Nuno Casimiro), o desígnio de dar a ver, da cidade, recantos inusitados ou interpretações diversas daqueles lugares, por mais familiares que sejam a quem os conhece, pela voz que nos encaminha. Depois do conceito do ponto de vista - de onde olha quem olha -, impõe-se o conceito da direcção do olhar, de como um olhar dirigido é mais atento, mais clarividente, mais disponivel para descobrir coisas que lá estavam, mas não eram vistas. Como escreve o Visões, em prefácio a esta edição, "acreditamos que as pessoas só ouvem o que já sabem e para que ouçam o que queremos dizer, temos de ser capazes de as desconcertar ou embalar". Essa intenção, a que chamaria engenharia do olhar, oferece aos sentidos - à audição, primeiro, à visão e ao tacto e ao olfacto, depois - a possibilidade de ler no tecido urbano e humano novos sentidos, de descodificar leituras outras em notícias velhas. A historicidade "oficial" embebida pelo recorte urbano é assim, passivel de ser desmontada, articulada com a múltipla historicidade individual, através das narrativas - fragmentárias, articuladas, que se atropelam e enriquecem mutuamente - que, essas sim, descobrimos com um olhar virgem. Desse confronto nasce o jogo ficcional: duvidamos se aquilo que nos é relatado se pode ou não furtar à categoria de "verdade". Esta destrinça talvez não tenha interesse para a fruição do objecto; mas passar por vielas e estradas com um guia que nos sopra ao ouvido e o olhar perdido entre dois prédios (sobre os quais julgamos saber tudo) é dar aos sentidos um alcance outro, de modo provocatório, porque oferece um estímulo principalmente intelectual.

A cidade como matéria suja, desabitada, e que amedronta, é o cerne do exercício desenvolvido em Coma profundo. A ameaça de um crime paira sobre esta história: quem não sentirá medo ao avançar por ruas estreitas, quando uma voz enumera devagarinho o que parecem ser os minutos antes do fim, quando alguém nos assusta dizendo que estamos a ser observados, quando essa mesma voz teme ter seguido - e nós com ela - o caminho errado? 0 guia é o nosso garante, a certeza de que os seus passos guiarão os nossos e que nada de ominoso acontecerá; mas mesmo nele não sabemos se podemos confiar, pois relata episódios que cremos reais, mas cujo carácter surreal nos convence de que a realidade é mais surpreendente que a ficção: "à nossa direita podemos observar a Capela de Nossa Senhora da Conceição. Desconhece-se a data e o objectivo da sua construção, já que os documentos que continham essa informação desapareceram em circunstâncias pouco claras. Ao fundo, podemos observar a extensão do largo da capela, executada em 2001 no âmbito dos programas de requalificação urbana da Capital Europeia da Cultura. Actualmente, a capela está encerrada. Abre apenas no dia treze de cada mês, para que a Venerável Ordem de Malta possa executar o seu ritual nocturno".

Em Coma profundo, os discursos cruzados têm origens diversas: o rádio do táxi, uma aula de psicologia social, o testemunho de um carpinteiro ou a notícia da morte do homem que o tinha contratado para reparar o estuque do tecto. As narrativas fragmentárias alimentam a sensação de ameaça, a que a banda-sonora só vem acrescentar uma ambiência intimidatória. É, aliás, também do delicado trabalho musical e de sonoplastia de João Martins que ressurge a tentação de não confiar em quem nos guia: acreditamos que nos diga que "aquele bebedouro é ao mesmo tempo lampião e pelourinho", mas percebemos que estamos a ser manipulados quando o som da água a correr, que vemos à nossa frente e nos precipitamos para sentir, está, afinal, gravado como tudo o resto.

A manipulação da verdade - ou a mentira que a verdade inclui, resultado das subjectividades em jogo, que 
Errare,

vista de uma das

paisagens por onde passa o espectador e onde se evidencia um grafito feito pelo Visões Úteis, fot. João Martins.

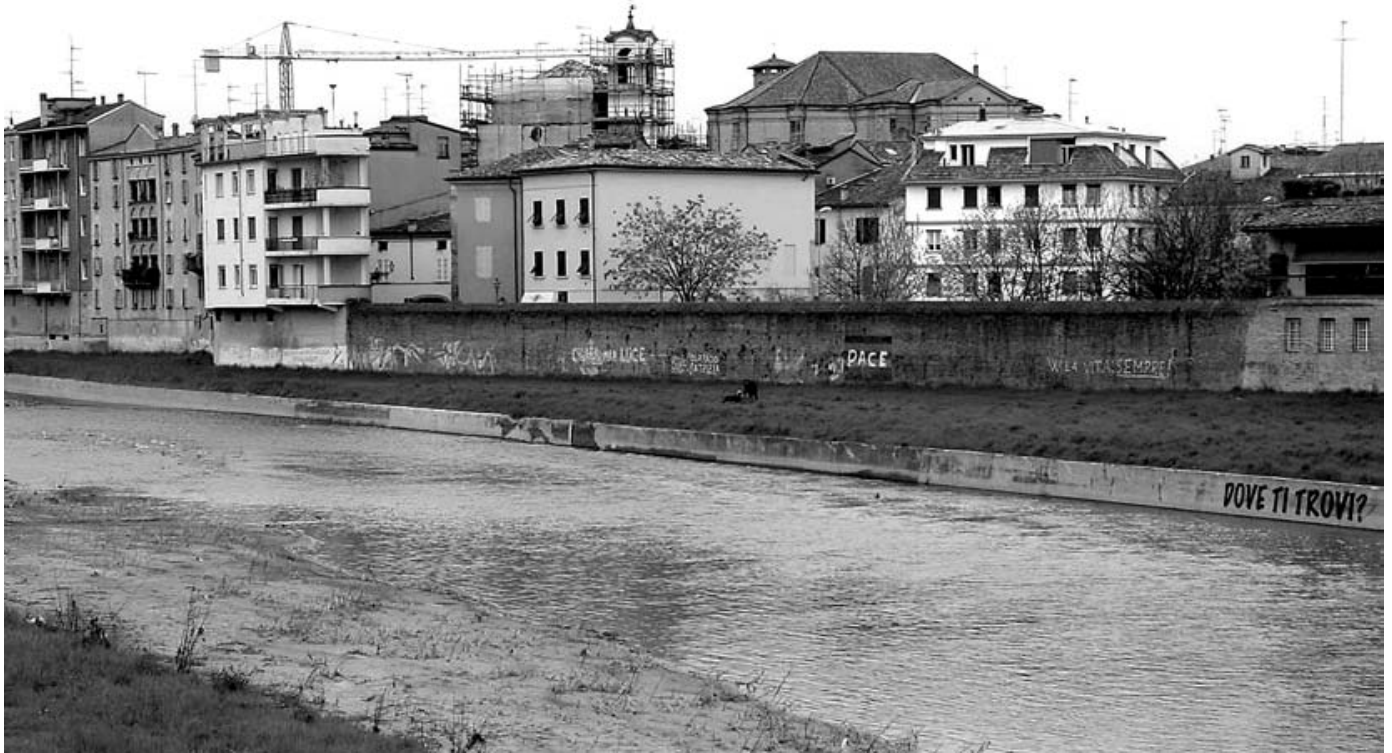

redistribui noções tão pessoais como fé, identidade, sentido de pertença - é continuada, senão reforçada, em Errare ${ }^{4}$. Novamente, somos confrontados com um mistério: um homem desapareceu e o seu irmão tenta encontrá-lo, o que o leva a uma cidade que desconhece. Importa por isso saber que, na língua italiana, errare tem igualmente o duplo sentido que no português - errar é incorrer em engano e também vaguear, andar sem rumo certo.

0 dispositivo dramatúrgico desenvolvido pela companhia é aqui mais rico: desaparece a figura do guia e quem agora se assume como narrador é o protagonista da história, que, ao contrário de nos conduzir - na posição superior de quem sabe por onde vamos -, pede a nossa ajuda, solicita a nossa companhia para a sua demanda por um caminho desconhecido. É outro o grau de envolvimento na história: quem connosco erra não sabe mais do que nós. Vale-se do mesmo que, em Coma profundo, era fornecido ao aventureiro: uma gravação sobre cujas indicações recaem as mesmas suspeitas de veracidade. A subtileza é outra: o irmão desaparecido deixa atrás de si uma cassete, que desde logo anuncia a manipulação que no anterior projecto era intuída: "faz de conta que isto é um jogo. Esta cidade construí-a eu. Tu andas por onde eu disser. Confia em mim". Uma dispersão narrativa similar interrompe a acção, fornecendo fragmentos de vivências: tanto no Porto como em Parma, fiç̧ões inspiradas e/ou influenciadas pela imponência ou degradação do espaço público, pela monocromia ou diversidade da fauna habitante ou passageira. Em Errare, cruzam-se com o nosso percurso um engenheiro, uma velha mulher, três prisioneiros ou uma funcionária de aeroporto, anunciando-se enquanto vozes cortadas, a cujo discurso é possivel atribuir um sentido. Como fazemos nos outros dias, quando apanhamos na rua e no supermercado frases soltas de conversas cujo encaixe nos cabe a nós inventar.

Mencionei há pouco os sentidos e talvez se estranhe que refira o tacto. Mas de que outra forma, segundo o existe mesmo? É ele quem aconselha: "se quiseres, passa a mão pela parede para saberes que estás vivo". Somos manipulados ao ponto de obedecer, porque deixámos lá atrás, suspensa como a roupa nos estendais, a hipótese da descrença. Porque nos sentimos perseguidos e ameaçados, ou porque nos sentimos perdidos e errantes: mas quando nos é sugerido entrar numa livraria, ou numa igreja (lugares de fé, e de solidão também), sabemos que mesmo entre o caos urbano, há sempre um refúgio possível. 0 nosso parceiro, porém, tem mais dificuldade em deixarse convencer, chega a ficar revoltado. Teme que tudo seja uma brincadeira: "Puseste toda a cidade a olhar para mim", queixa-se. Não é possivel evitar, mais uma vez, a sensação de estarmos a ser observados. Somos nós quem explora e desventra a cidade, ou é ela que segura um binóculo gigante voltado para nós? A rua, lugar de exposição, mostra-nos e mostra-se: quem dirige agora o olhar?

Mensagens em código, símbolos obscuros, palavras indecifráveis, sentidos baralhados. Abandonada a denúncia política sobre a cidade que não pára de crescer, tão presente em Coma profundo, uma postura forçada pela vivência quotidiana, no audiowalk de Parma já não sentimos essa urgência: porque lá o Visões Úteis, estrangeiro, foi também sujeito a um processo de descoberta da cidade. Mas se a dimensão politizada foi trocada pela reflexão memorialista, e se isso é evidenciado pela leitura, não deixa porém de se impor uma ressalva: a experiência dos projectos não pode ser subsumida à sua vertente textual. Se isso é verdade para qualquer texto teatral, que só a cena completa, aqui são mais as variáveis em falta: e as didascálias introduzidas no texto não conseguem acrescentar a trilha sonora e o imenso cenário que é a cidade. Por isso, em complemento a esta edição, é indispensável perder alguns minutos em www.visoesuteis.pt, descarregar para um disco os ficheiros e, se for possivel, ir até à Foz Velha do Porto ou ao posto de turismo de Parma e carregar no play. irmão desaparecido, saber se esta cidade em que estamos 